LOPES, C.A.; RITSCHEL, P.S.; VIEIRA, J.V.; LIMA, D.B. Comportamento de genótipos de cenoura para verão em localidades com diferentes etiologias da queima-das-folhas. Horticultura Brasileira, Brasília, v. 18 n. 2, p. 119-122, julho 2.000.

\title{
Comportamento de genótipos de cenoura para verão em localidades com diferentes etiologias da queima-das-folhas.
}

\author{
Carlos Alberto Lopes; Patrícia S. Ritschel; Jairo V. Vieira; Dejoel B. Lima \\ Embrapa Hortaliças, Caixa Postal 218, CEP 70.359-970 Brasília - DF. e-mail: clopes@cnph.embrapa.br
}

\begin{abstract}
RESUMO
Treze genótipos de cenoura de verão foram avaliados em 1997 e 1998 para a resistência ao complexo etiológico da queima-das-folhas em seis localidades apresentando infecção natural com os diferentes componentes deste complexo. Alternaria dauci foi o patógeno mais frequente, presente em todas as localidades e predominando em quatro delas. Cercospora carotae foi encontrado em três dos seis locais, prevalecendo em um deles. Estes dois patógenos estavam presentes em proporções similares em um dos locais. Xanthomonas campestris pv. carotae foi observada em todas as localidades, porém em intensidade sempre menor do que os dois fungos, sempre que estes últimos se encontravam presentes. Os genótipos 'Brasília', 'Alvorada', 'Tropical', 'Carandaí' e 'Kuronan', foram os mais resistentes, independentemente da composição local do complexo etiológico da doença. As cultivares Nova Kuroda e Prima foram as mais suscetíveis à doença.
\end{abstract}

Palavras-chave: Alternaria dauci, Cercospora carotae, Xanthomonas campestris pv. carotae, Daucus carota, resistência a doenças.

\section{ABSTRACT}

Behavior of summer carrot genotypes in fields with different etiologies of the leaf blight complex.

Thirteen carrot genotypes were evaluated for their resistance to the leaf blight complex in six locations in Brazil. The assessments were carried out under field conditions, in the summer of 1997 and 1998 , in plots where each of the pathogens were involved differentially in the composition of the complex. Alternaria dauci was the most frequent pathogen, being found in all locations and predominating in four of them. Cercospora carotae was found in three out of the six locations, predominating in one of them. These two species were found in equal proportions in one field. Xanthomonas campestris pv. carotae was present in all sampled plots, but in lower intensity when compared to the two fungi. The cultivars Brasilia, Alvorada, Tropical, Carandai and Kuronan were the most resistant, independently of the composition of the pathological complex. 'Nova Kuroda' and 'Prima' were the most susceptible.

Keywords: Alternaria dauci, Cercospora carotae, Xanthomonas campestris $p v$. carotae, Daucus carota, disease resistance.

(Aceito para publicação em 09 de março de 2.000)

\begin{abstract}
A queima-das-folhas, causada pelo complexo patológico formado por Alternaria dauci (Kuhn) Groves \& Skolko, Cercospora carotae (Pass) Solheim e Xanthomonas campestris pv. carotae (Kendrick) Dye é o fator mais limitante à cultura da cenoura (Daucus carota L.) cultivada no verão brasileiro. Os três patógenos podem ocorrer ao mesmo tempo na planta e causam sintomas similares, mesmo quando infectando individualmente a folhagem (Reifschneider, 1980; Reifschneider et al., 1984).
\end{abstract}

Na busca de informações para o controle da doença por meio da resistência genética, cultivares de cenoura têm sido avaliadas para resistência à queima-dasfolhas em diferentes localidades no Brasil. Na maioria destas avaliações, entretanto, faz-se referência à presença de apenas um dos patógenos, A. dauci, como em trabalhos realizados em Brasília, DF (Boiteux et al., 1983; Aguilar et al., 1986); em Uberlândia, MG (Oliveira Filho et al., 1990); em Bandeirantes, PR (Juliatti et al., 1987); em Goiânia, GO (Sonnenberg et al., 1979); em Guaramiranga, CE (Muniz \& Ponte, 1988), em Mogi das Cruzes, SP (Costa et al.,1974) e em Vitória de Santo Antão, PE (Melo et al., 1979). Já nos municípios de Guaramiranga, CE (Muniz \& Magalhães, 1984) e Uberlândia, MG (Brito et al., 1997), as avaliações foram feitas em campos onde $A$. dauci e $C$. carotae participavam do processo infeccioso, embora, no último caso, $A$. dauci tivesse alta predominância.

Apesar de A. dauci ter se mostrado o mais freqüente e o mais agressivo dos três patógenos em cenoura, $C$. carotae tem predominado em algumas áreas de cultivo (Reifschneider, 1983), podendo requerer estratégia de controle diferenciada para a doença.

O objetivo deste trabalho foi investigar a etiologia da queima-das-folhas e avaliar um conjunto de cultivares de cenoura recomendadas para o cultivo de verão em seis regiões produtoras de cenoura no Brasil, visando orientar o processo de seleção de cultivares resisten- tes à doença bem como a produção de sementes destas cultivares.

\section{MATERIAL E MÉTODOS}

A severidade da doença e a contribuição individual dos patógenos Alternaria dauci (AD), Cercospora carotae (CC) e Xanthomonas campestris pv. carotae (XCC) na manifestação da queima-das-folhas foi avaliada em 13 genótipos de cenoura cultivadas, durante o verão, em 1997 e 1998. Esses genótipos consistiram de duas populações, cinco cultivares e seis seleções da cv. Brasília, que é hoje cultivada em mais de $70 \%$ da área produtora de cenoura no Brasil. Os experimentos foram realizados em campos sob infestação natural dos patógenos em seis localidades: Embrapa Hortaliças, Brasília, DF; Núcleo Rural da Vargem Bonita, Brasília, DF; Núcleo Rural de Alexandre Gusmão, Brasília, DF; São Gotardo, MG; Carandaí, MG e Irecê, BA, como parte de um ensaio regional de cultiva- 
res conduzido pela Embrapa Hortaliças. Cada parcela foi constituída de $4 \mathrm{~m}^{2}$ de canteiro contendo aproximadamente 360 plantas, com três repetições. A severidade da doença foi avaliada em cada parcela segundo uma escala de notas que variou de 1 a 5 , onde 1 representava ausência de sintomas e 5 queima total das folhas. A avaliação foi feita por dois avaliadores, e os valores representados pela média das duas leituras.

Para a análise etiológica, entre cinco e dez folhas com sintomas característicos da doença foram colhidas das plantas em cada local de plantio, por ocasião da colheita das raízes, de modo que diferentes idades de folha das plantas fossem amostradas, quando possível. As folhas foram levadas em sacos de papel para o laboratório e submetidas por 24-48 horas à câmara úmida formada em sacos de plástico vedados contendo um chumaço de algodão umedecido em água destilada esterilizada em seu interior. A seguir, dez lesões individuais de cada amostra foram cortadas pela metade com bisturi flambado, em seções de aproximadamente $2 \times 2 \mathrm{~mm}$, e examinadas em microscópio ótico Olympus com objetiva 10 e ocular 12,5 para determinar a presença de esporos dos fungos e de exsudação de fluxo bacteriano. Para cada localidade, foram examinadas 30 seções de folíolos por genótipo, em três repetições.

\section{RESULTADOS E DISCUSSÃO}

$\mathrm{Na}$ análise etiológica, verificou-se a predominância de $\mathrm{AD}$ em quatro das seis localidades amostradas em 1997 e 1998 (Tabela 1), indicando que este é o patógeno mais freqüente do complexo. Este resultado está em concordância com o relato de Reifschneider (1983) e justifica os maiores esforços dos programas de melhoramento visando resistência à doença com esta etiologia (Boiteux et al., 1983). CC prevaleceu sobre AD somente no Núcleo Rural de Alexandre Gusmão, no Distrito Federal, embora tivesse alta incidência também no campo experimental da Embrapa Hortaliças. Proporções similares dos patógenos foram encontradas quando estas mesmas localidades do Distrito Federal foram amostradas neste trabalho e no levanta-

Tabela 1. Freqüência da ocorrência de Alternaria dauci (AD), Cercospora carotae (CC) e Xanthomonas campestris pv. carotae (XCC) em lesões de folhas de cenoura cultivada no verão em diferentes localidades/anos. Valores em porcentagem do número de contagens. Brasília, Embrapa Hortaliças, 1997/1998.

\begin{tabular}{|c|c|c|c|c|c|}
\hline \multirow{2}{*}{$\begin{array}{l}\text { Localidade } 1 / \\
\text { ano }\end{array}$} & \multirow{2}{*}{$\begin{array}{l}\mathrm{N}^{\circ} \text { de lesões } \\
\text { analisadas }^{2}\end{array}$} & \multirow{2}{*}{$\begin{array}{c}\mathrm{N}^{\circ} \text { de } \\
\text { contagens }^{3}\end{array}$} & \multicolumn{3}{|c|}{ Freqüência (\%) } \\
\hline & & & AD & CC & $\overline{X C C}$ \\
\hline S. Gotardo/97 & 420 & 341 & 98,2 & 0,0 & 1,8 \\
\hline S. Gotardo/98 & 420 & 397 & 97,7 & 0,0 & 2,3 \\
\hline $\mathrm{CNPH} / 97$ & 390 & 416 & 37,3 & 57,7 & 5,0 \\
\hline CNPH/98 & 420 & 650 & 48,2 & 45,5 & 6,3 \\
\hline V. Bonita/97 & 420 & 398 & 98,0 & 1,3 & 0,7 \\
\hline A. Gusmão/97 & 420 & 398 & 13,8 & 79,9 & 6,3 \\
\hline Irecê/98 & 390 & 79 & 90,0 & 0,0 & 10,0 \\
\hline Carandaí/98 & 420 & 455 & 88,4 & 0,0 & 11,6 \\
\hline
\end{tabular}

${ }^{1} \mathrm{~S}$. Gotardo = São Gotardo, MG; CNPH = Embrapa Hortaliças, Brasília, DF; V. Bonita = Núcleo Rural de Vargem Bonita, Brasília, DF; A. Gusmão = Núcleo Rural Alexandre Gusmão, Brasília, DF; Irecê, BA; Carandaí, MG.

${ }^{2}$ Número de lesões foliares analisadas para a presença dos patógenos da queima-das-folhas.

${ }^{3}$ Número de lesões contendo cada patógeno. Obs. uma lesão foi contada mais de uma vez em caso de infecção com mais de um patógeno

mento feito há mais de 15 anos (Reifschneider, 1983). Isto indica que a pressão de seleção sobre o patógeno, pela adoção de uma cultivar resistente, como a 'Brasília', não provocou alterações discerníveis nas populações dos componentes do complexo.

Observou-se ainda que, baseado nos dados obtidos na Embrapa Hortaliças, somente se pode inferir sobre a resistência à "queima" causada por $\mathrm{CC}$ ou $\mathrm{XCC}$ em genótipos resistentes a AD. Isto porque a presença destes patógenos somente pode ser observada na disponibilidade de tecido foliar resultante da resistência a $\mathrm{AD}$, patógeno mais agressivo e que ataca a planta em estádios de crescimento menos avançados. Este fato pode ser comprovado quando as parcelas testemunhas da cultivar Nantes foram totalmente destruídas por $\mathrm{AD}$ na Embrapa Hortaliças, em 1997 (dados não publicados), enquanto outros genótipos avaliados apresentaram os dois fungos em proporções similares. Em 'Nantes', que é extremamente suscetível ao ataque de $\mathrm{AD}$, não foi possível detectar CC, por falta de área foliar disponível ao ataque deste último, embora se soubesse que este estava presente no campo. Como consequência, a resistência a AD incorporada nas cultivares de lançamento mais recente têm proporcionado observações mais freqüen- tes de $\mathrm{CC}$ e XCC, dando até uma idéia superestimada da importância econômica destes agentes etiológicos.

Embora quase sempre presente nas localidades, a incidência de XCC sempre foi bem menor do que a do fungo mais frequente. Como não foi observada interação significativa entre cultivar $\mathrm{X}$ patógeno na análise estatística, a prevalência do patógeno por localidade é representada pela média das cultivares (Tabela 1). A alta prevalência de AD em São Gotardo, Irecê, Carandaí e Vargem Bonita (DF) e de CC em Alexandre Gusmão (DF) indicam que germoplasma eventualmente selecionado nestas localidades em programas de melhoramento podem acumular diferentes freqüências de genes de resistência a estes patógenos. Nos campos experimentais da Embrapa Hortaliças, ambos $\mathrm{CC}$ e $\mathrm{AD}$ encontram ambiente favorável, tendo sido encontrados em proporções similares (Tabela 1). É provável que esta situação tenha sido favorável durante a seleção da cultivar Brasília, que tem mostrado alto nível de resistência ao complexo queima-das-folhas em diferentes localidades do Brasil, independente do patógeno prevalecente (Tabela 2). Entretanto, estudo visando avaliar a independência de genes de resistência para cada um dos patógenos do complexo necessita ser melhor avalia- 
Tabela 2 Reação de genótipos de cenoura à infecção natural da queima-das-folhas em diferentes localidades e anos. Brasília, Embrapa Hortaliças, 1997/1998.

\begin{tabular}{|c|c|c|c|c|c|c|c|c|c|}
\hline \multirow{2}{*}{ Genótipo } & \multicolumn{8}{|c|}{ Localidade $^{1}$ / ano } & \multirow{2}{*}{ Média } \\
\hline & SG/97 & SG/98 & CNPH/97 & CNPH/98 & VB/97 & AG/97 & IR/98 & CAR/98 & \\
\hline Brasília² & $2,5 \mathrm{c}^{3}$ & $2,8 a$ & $1,8 \mathrm{~d}$ & $3,0 \mathrm{e}$ & $2,6 \mathrm{c}$ & $2,2 \mathrm{de}$ & $2,4 a$ & $3,8 \mathrm{bc}$ & 2,6 \\
\hline L 971275 & $2,6 \mathrm{c}$ & $3,5 \mathrm{a}$ & $2,1 \mathrm{~d}$ & - & 3,2 bc & $2,1 \mathrm{e}$ & $3,4 \mathrm{a}$ & $4,0 \mathrm{~b}$ & 3,0 \\
\hline Carandaí & $2,6 \mathrm{c}$ & $3,3 a$ & $3,7 a b c$ & $4,0 \mathrm{bcd}$ & $2,9 \mathrm{c}$ & 2,7 cde & $3,0 \mathrm{a}$ & $3,1 \mathrm{c}$ & 3,2 \\
\hline Alvorada & $2,6 \mathrm{c}$ & $3,1 \mathrm{a}$ & $2,2 \mathrm{~d}$ & $4,2 \mathrm{bcd}$ & $3,1 \mathrm{bc}$ & $2,4 \mathrm{de}$ & $3,6 \mathrm{a}$ & $4,0 \mathrm{~b}$ & 3,2 \\
\hline L 931175 & $3,0 \mathrm{c}$ & -4 & $2,2 \mathrm{~d}$ & $4,1 \mathrm{bcd}$ & $3,4 \mathrm{bc}$ & $2,6 \mathrm{cde}$ & - & - & 3,1 \\
\hline Kuronan S & $2,7 \mathrm{c}$ & $3,4 a$ & $2,6 \mathrm{~cd}$ & $3,9 \mathrm{~cd}$ & $3,8 \mathrm{abc}$ & 3,1 bcde & $2,8 \mathrm{a}$ & $3,9 \mathrm{bc}$ & 3,3 \\
\hline Brasília AS & $2,9 \mathrm{c}$ & $4,0 \mathrm{a}$ & $2,3 \mathrm{~d}$ & - & $3,5 a b c$ & 2,8 cde & $2,8 \mathrm{a}$ & $3,9 \mathrm{bc}$ & 3,2 \\
\hline Brasília RL & $2,9 \mathrm{c}$ & $3,3 a$ & $2,8 \mathrm{bcd}$ & $3,8 \mathrm{~d}$ & $3,3 \mathrm{bc}$ & $3,4 \mathrm{bcd}$ & $3,0 \mathrm{a}$ & $3,6 \mathrm{bc}$ & 3,4 \\
\hline Tropical & $3,1 \mathrm{c}$ & $3,6 \mathrm{a}$ & $2,8 \mathrm{bcd}$ & $4,5 a b c$ & 3,3 bc & 3,0 cde & $2,4 \mathrm{a}$ & $4,0 \mathrm{~b}$ & 3,3 \\
\hline Brasília² & $3,0 \mathrm{c}$ & $3,6 \mathrm{a}$ & $2,7 \mathrm{bcd}$ & $3,9 \mathrm{~cd}$ & $3,4 \mathrm{bc}$ & $2,2 \mathrm{e}$ & $2,8 \mathrm{a}$ & $3,6 \mathrm{bc}$ & 3,2 \\
\hline Brasília S & $3,4 \mathrm{bc}$ & $3,9 a$ & $2,8 \mathrm{bcd}$ & $4,6 a b$ & 3,4 bc & $3,6 \mathrm{bc}$ & $3,0 \mathrm{a}$ & $4,3 a b$ & 3,6 \\
\hline N Kuroda & $4,1 a b$ & $4,4 \mathrm{a}$ & $3,9 a b$ & $5,0 \mathrm{a}$ & $4,5 a b$ & $4,9 a$ & $3,3 \mathrm{a}$ & $5,0 \mathrm{a}$ & 4,4 \\
\hline Prima & $4,4 \mathrm{a}$ & $3,9 a$ & $4,4 \mathrm{a}$ & $5,0 \mathrm{a}$ & $4,8 \mathrm{a}$ & $4,2 \mathrm{ab}$ & - & $4,1 \mathrm{~b}$ & 4,4 \\
\hline C.V. & 11,51 & 17,21 & 14,42 & 6,31 & 15,87 & 15,03 & 17,96 & 8,77 & \\
\hline
\end{tabular}

': SG = São Gotardo, MG; CNPH = Embrapa Hortaliças, Brasília, DF; VB = Núcleo Rural de Vargem Bonita, Brasília, DF; AG = Núcleo Rural Alexandre Gusmão, Brasília, DF; IR = Irecê, BA; CAR = Carandaí, MG.

2: Cultivar Brasília produzida por firmas diferentes.

3: Médias seguidas da mesma letra, na coluna, não diferem estatisticamente entre si (Tuckey, $\mathrm{P}=0,05$ ).

(Média das notas de dois avaliadores, de 1 a 5 , onde 1 representou ausência de sintomas e 5 queima total da folhagem).

${ }^{4}$ : Avaliação não realizada.

da no Brasil, e estudos neste sentido encontram-se em andamento na Embrapa Hortaliças.

O fato de 'Brasília' ter sido selecionada basicamente na Embrapa Hortaliças permitiu que, além da resistência a $\mathrm{AD}$, seleção fosse feita também para $\mathrm{CC}$ e XCC, patógenos que também encontram condições ambientais favoráveis para desencadear epidemias no verão desta localidade. Entretanto, esta cultivar apresenta alguma suscetibilidade a CC em condições de campo (Reifschneider, 1984).

Houve uma tendência de os genótipos mais resistentes assim se comportarem nas diferentes localidades (Tabela 2), independentemente da composição etiológica do complexo patológico. Por exemplo, foi observada uma correlação de 69 \% quando se compararam os 13 genótipos em Vargem Bonita e em Alexandre Gusmão, onde predominaram $\mathrm{AD}$ e $\mathrm{CC}$, respectivamente. Embora não muito alta, esta correlação pode ser parcialmente explicada pelo "pool" gênico utilizado no melhoramento genético, que provavelmente confere resistência do tipo horizontal a mais de uma doença (Vieira \& Casali, 1984).

O comportamento diferenciado dos genótipos derivados da cultivar Brasília (Tabela 2) sugere que o processo de seleção utilizado na obtenção destes foi executado em localidades com diferentes intensidades da doença; sem a devida pressão de seleção, a frequência de alelos desejáveis é diminuída, com reflexo no nível de resistência.

Os resultados apresentados fortalecem a necessidade de se avaliarem populações avançadas, de programas de melhoramento, em diferentes localidades. Além disso, para fins de produção de sementes, a manutenção da população (cultivar) também requer exposições temporárias à doença, de modo a garantir a estabilidade da frequência gênica desejável nos indivíduos selecionados.

\section{AGRADECIMENTOS}

À Emater-MG, Emater DF, EPABA e COOPADAP-São Gotardo pelo apoio na instalação e avaliação das parcelas experimentais; a Joaquim Olímpio, pelo apoio laboratorial, a João Lopes pelo apoio na condução do experimentos e a
Francisco Reifschneider e Leonardo Boiteux , pela leitura crítica do manuscrito e sugestões.

\section{LITERATURA CITADA}

AGUILAR, J.A.E.; REIFSCHNEIDER, F.J.B.; ROSSI, P.F.E.; DELLA VECCHIA, P.T. Nível de resistência de cenoura a Alternaria dauci e interação com tratamento químico. Horticultura Brasileira, Brasília, v. 4, n. 2, p. 19-22, 1986.

BOITEUX, L.S.; DELLA VECCHIA, P.T.; REIFSCHNEIDER, F.J.B. Heritability estimate for resistance to Alternaria dauci in carrot. Plant Breeding, Berlin, v. 110, p. 165167, 1993.

BRITO, C.H.; POZZA, E.A.; JULIATTI, F.C.; LUZ, J.M.Q.; PAES, J.M.V. Resistência de cultivares de cenoura (Daucus carota L.) à queima das folhas durante o verão. Revista Ceres, Viçosa, v. 44, n. 253, p. 371-379, 1997.

COSTA, C.P.; IKUTA, H.; BAKER, L.R.; SILVA, N. Resistência de campo em cenoura (Daucus carota L.) à Alternaria dauci (Kuehn) Groves \& Skolko. Relatório Científico do Instituto de Genética da ESALQ, Piracicaba, n. 8, p. 58-60, 1974.

JULIATTI, F.C.; REGHIN, M.Y.; BUENO, J.T.; CANDIOTO, W. Comportamento de cultivares de cenoura e resistência à queima das folhas na semeadura de outubro em Bandeirantes, PR. Fitopatologia Brasileira, Brasília, v. 12, n. 1, p. 133, 1987. 
MELO, P.C.T.; WANDERLEY, L.J.G.; MENEZES, D. Resistência de cultivares de cenoura Daucus carota L. á Alternaria solani Kuehn Groves \& Skolko em condições de campo. In: CONGRESSO BRASILEIRO DE OLERICULTURA, 19, 1979, Florianópolis, SC. Resumos ... Florianópolis: SOB, 1979, v. 1, p. 314-314.

MUNIZ, J.O.L.; PONTE, J.J. Resistência de cultivares de cenoura à queima das folhas na Serra de Baturité, Estado do Ceará (Brasil). Fitopatologia Brasileira, Brasília, v. 13, n. 1, p. 48-51, 1988.

MUNIZ, J.O.L.; MAGALHÃES, C.A. Resistência de cultivares de cenoura (Daucus carota L.) à queima das folhas em Guaramiranga Ceará. Fortaleza: EPACE, 1984. 12 p. (Boletim de Pesquisa, 4).
OLIVEIRA FILHO, G.M.; JULIATTI, F.C.; KERR, W.E. Uberlândia: nova cultivar de cenoura resistente à Alternaria dauci. Fitopatologia Brasileira, Brasília, v. 15, n. 2, p. 150, 1990.

REIFSCHNEIDER, F.J.B. Levantamento e flutuação da ocorrência de Alternaria dauci, Cercospora carotae e Xanthomonas campestris pv. carotae no Distrito Federal. Fitopatologia Brasileira, Brasília, v. 8, n. 3, p. 607, 1983.

REIFSCHNEIDER, F.J.B. Queima das folhas da cenoura, um complexo patológico. Fitopatologia Brasileira, Brasília, v. 5, n. 3, p. 445-446, 1980.
REIFSCHNEIDER, F.J.B.; TAKATSU, A.; LOPES, C.A. Crestamento bacteriano da cenoura causado por Xanthomonas campestris pv. carotae no Distrito Federal. Fitopatologia Brasileira, Brasília, v. 9, n. 2, p. 189-192, 1984.

REIFSCHNEIDER, F.J.B. Doenças fúngicas e bacterianas da cenoura - sintomatologia e controle. Informe Agropecuário, Belo Horizonte, v. 10 , n. 120 , p. 40-43, 1984.

SONNENBERG, P.E.; MONTEIRO, M.S.R; MARTINS, J.C. Comportamento dos cultivares de cenoura (Daucus carota L.) 'Tropical', 'Nantes' e 'Kuroda', em diferentes épocas do ano. Revista de Olericultura, Campinas, v. 17, p. 178-185, 1979.

VIEIRA, J.V.; CASALI, V.W.D. Melhoramento de cenoura para verão. Informe Agropecuário, Belo Horizonte, v. 10, n. 120, p. 17-18, 1984 